Relato de experiência

\title{
Decifrando enigma em tempos de pandemia: a resolução de problemas como metodologia na aula de matemática do 60 ano
}

\author{
Deciphering puzzles in times of pandemic: problem solving as a methodology for \\ mathematics class with 6 graders \\ Descifrando enigma en tiempos de pandemia: resolución de problemas como metodología \\ en la clase de matemáticas de 60 año \\ Leticia Diello Kuhn ${ }^{1}$ \\ [0000-0003-2096-861X] \\ Clarissa Coragem Ballejo ${ }^{2}$ \\ [0000-0003-4140-9550] \\ Elisabete Rambo Braga ${ }^{3}$ \\ [0000-0003-0807-8729]
}

\section{Resumo}

O presente relato tem por finalidade compartilhar uma experiência no emprego da metodologia de resolução de problemas fundamentada nas concepções de George Polya em uma aula de Matemática na modalidade online, ocorrida no período da pandemia da COVID-19. Tal prática foi realizada com estudantes do $6^{\circ}$ ano do Ensino Fundamental de uma escola da rede privada de Porto Alegre - RS. A atividade, denominada "Decifrando o enigma", cujo objetivo principal culminou na formação de uma frase secreta a partir da solução de alguns desafios matemáticos em arquivos codificados por senhas, foi dividida em quatro etapas: iniciando a atividade, definindo estratégias, executando o plano e refletindo sobre a atividade. Ressalta-se que cada uma dessas fases corresponde às etapas propostas pelo referido teórico, a saber: compreensão do problema, estabelecimento de um plano, execução e retrospecto. Tal prática foi muito elogiada pelos estudantes que se sentiram desafiados e puderam trabalhar em equipes, mesmo que remotamente. Considera-se que o uso de recursos digitais deve estar relacionado a aulas que busquem por inovações e não somente réplicas de práticas já conhecidas e aplicadas sem a utilização destas ferramentas.

Palavras-chave: Resolução de problemas. Ensino Fundamental. Ensino Remoto.

\begin{abstract}
The present report has the purpose of sharing an experience in the usage of the problem solving methodology based on George Polya's conceptions in a mathematics lecture, taught online, which occurred during the pandemic period of COVID-19. This practice was carried out with students from the 6th year of elementary school at a private school in Porto Alegre - RS. The activity, called "Deciphering the enigma", which its main objective culminated in the formation of a passphrase based
\end{abstract}

\footnotetext{
${ }^{1}$ leticiadiello@gmail.com, Mestranda em Educação em Ciências e Matemática pela Pontifícia Universidade Católica do Rio Grande do Sul (PUCRS), Professora de Matemática da Educação Básica na rede municipal, Porto Alegre/Rio Grande do Sul/Brasil.

${ }^{2}$ clarissa.ballejo@acad.pucrs.br, Doutora em Educação em Ciências e Matemática pela Pontifícia Universidade Católica do Rio Grande do Sul (PUCRS), Professora de Matemática da Educação Básica na rede privada, Porto Alegre/Rio Grande do Sul/ Brasil.

3 elisabete.braga@edu.pucrs.br, Doutoranda em Educação em Ciências e Matemática pela Pontifícia Universidade Católica do Rio Grande do Sul (PUCRS), Professora de Matemática da Educação Básica na rede privada, Porto Alegre/Rio Grande do Sul/Brasil.
} 
on the solution of some mathematical challenges in password-encoded files. The task was divided into four stages: starting the activity, defining, carrying out the plan and reflecting on the activity. It is noteworthy that each of these phases corresponded to one of the subdivisions proposed by the referred theorist: understand the problem, devise a plan, carry out the plan and review the entire process. This practice was highly praised by students who felt challenged and were able to work in teams, even if remotely. Additionally, it is considered that the use of digital resources must be done in classes that seek innovation and not only replicate lectures already applied without the utilization of such tools.

Keywords: Problem Solving. Elementary School. Distance Learning.

\section{Resumen}

El propósito de este informe es compartir una experiencia en el uso de la metodología de resolución de problemas basada en las concepciones de George Polya en una clase de matemáticas en la modalidad online, ocurrida durante el período pandémico del COVID-19. Esta práctica se llevó a cabo con alumnos de 6 ㅇ de primaria de un colegio particular de Porto Alegre - RS. La actividad, denominada "Descifrando enigma", cuyo objetivo principal culminó en la formación de una frase secreta a partir de la solución de algunos desafíos matemáticos en archivos codificados por contraseñas, se dividió en cuatro etapas: inicio de la actividad, definición de estrategias, ejecución del plan y reflexión de la actividad. Es de destacar que cada una de estas fases corresponde a los pasos propuestos por el referido teórico, a saber: comprensión del problema, establecimiento de un plan, ejecución y retrospectiva. Esta práctica fue muy elogiada por los estudiantes que se sintieron desafiados y pudieron trabajar en equipo, incluso de forma remota. Se considera que el uso de recursos digitales debe estar relacionado con clases que busquen innovaciones y no solo réplicas de prácticas ya conocidas y aplicadas sin el uso de estas herramientas.

Palabras claves: Resolución de problemas. Educación Primaria. Enseñanza remota.

\section{Introdução}

Diante da realidade enfrentada pela situação da pandemia da COVID-19, a educação teve de passar por diversas mudanças e adaptações, visando a reinvenção. Neste novo cenário, os professores que passaram a ministrar aulas online tiveram de se adaptar a essa configuração, buscando meios de adequar, ajustar e inovar suas aulas.

Assim, o uso das Tecnologias Digitais de Informação e Comunicação (TDIC) foram fundamentais para a continuidade das aulas na modalidade remota e teve seu processo de integração na educação básica - que já estava em curso - acelerado pela situação da pandemia. Cani et al. (2020) corroboram essa ideia ao afirmarem que as TDIC passaram de um uso esporádico para obrigatório. Salienta-se que tais recursos já vinham sendo validados na Base Nacional Comum Curricular (BNCC) por meio do "reconhecimento das potencialidades das tecnologias digitais para a realização de uma série de atividades relacionadas a todas as áreas do conhecimento." (BRASIL, 2018, p. 474).

Em um mundo cada vez mais interconectado, o mercado de trabalho passou a exigir, além da formação técnica, habilidades socioemocionais. Nesse ambiente é necessária a combinação de características "cognitivas, interpessoais e intrapessoais como colaboração e trabalho em equipe, criatividade e imaginação, pensamento crítico e resolução de problemas" (VALENTE, 2018, p. 24), que devem ser apreendidas pelos futuros profissionais, mediante o uso das tecnologias digitais inseridas no processo de ensino e aprendizagem. De acordo com 
Pontes (2019), o currículo da Matemática deve estar em sintonia com as necessidades deste mundo tecnológico, uma vez que toda criança deste século "está intuitivamente relacionada e adaptada às novas tecnologias." (PONTES, 2019, p. 4).

Mais especificamente, a Educação Matemática pode contribuir para o desenvolvimento de tais competências e o emprego da resolução de problemas, como uma escolha metodológica no processo de ensino e aprendizagem, pode se mostrar favorável à criação de momentos que promovem a análise da situação, a seleção de estratégias, a elaboração de justificativas e o estabelecimento de generalizações. (WALLE, 2009). Além disso, a resolução de problemas estabelece uma dinâmica diferente em sala de aula, visto que os discentes assumem um papel de protagonismo próprio do método que gera um convite para a participação mais ativa na sala de aula - nesse caso, exclusivamente, virtual.

Nesta perspectiva, este relato tem por objetivo compartilhar uma experiência no emprego da metodologia de resolução de problemas fundamentada nas concepções de George Polya em uma aula de Matemática na modalidade online. Tal atividade, denominada de "Decifrando o enigma", foi aplicada com cinco turmas de 60 ano de uma escola da rede privada de Porto Alegre, RS. Suas etapas serão descritas e analisadas na sequência.

\section{Marco teórico}

O emprego da resolução de problemas como metodologia no processo de ensino e aprendizagem possibilita a construção de conceitos, o desenvolvimento de procedimentos e de atitudes matemáticas. Ademais, tal procedimento propicia ao estudante o enfrentamento de novas situações, o envolvimento com as aplicações da Matemática, tornando as aulas mais interessantes e desafiadoras. Para tanto, o discente passa a ter maior responsabilidade pela sua aprendizagem e, consequentemente, o docente deixa de ser o personagem central desse processo (ONUCHIC; ALLEVATO, 2011).

\subsection{Exercícios e problemas matemáticos}

Considera-se que problemas são situações que exigem a construção de estratégias que possibilitam o aprimoramento do conhecimento durante a elaboração de sua resolução. Pontes $(2019$, p. 4) afirma que "um verdadeiro problema deve se constituir um real desafio em que os alunos, por meios de sequências de ações, buscarão obter os resultados". Para Vianna (2002) uma situação pode ser caracterizada como problema quando não há um método determinado para solucioná-lo. Tal definição remete ao fato de que aquilo que para alguns é um problema, para outros pode não passar de um exercício. Da mesma forma, um exercício para quem não sabe utilizar estratégias próprias para a resolução pode ser classificado como um problema. Esses aspectos foram destacados ainda nos Parâmetros Curriculares Nacionais (PCNS), em 1998, ao descreverem que "o que é problema para um aluno pode não ser para outro, em função do seu nível de desenvolvimento intelectual e dos conhecimentos que dispõe" (BRASIL, 1998, p. 43).

Nesse contexto, é pertinente diferenciar problemas e exercícios a fim de empregá-los adequadamente no ensino da Matemática. O problema exige interpretação, invenção e criação de estratégias, enquanto o exercício se restringe à mera aplicação de fórmulas ou processos operatórios (BRASIL, 1998). Maia e Proença (2016) ressaltam que a diferenciação entre problema e exercício é um dos maiores obstáculos para os professores atualmente. 
Já a Base Nacional Comum Curricular (BNCC), promulgada em 2018, definiu que a resolução de problemas em diversos contextos necessita ser trabalhada com o compromisso de desenvolver o letramento matemático. Tal processo está inserido na atividade matemática, constituindo "objeto e estratégia" (BRASIL, 1998, p. 266) para a aprendizagem no decorrer do Ensino Fundamental.

Além disso, Echeverría (1998) afirma que atividades que se restringem a aplicação de algoritmos ou fórmulas conhecidas não podem ser classificadas como problemas. Vianna (2002) reforça essa ideia salientando que questões já conhecidas pelos discentes não podem ser denominadas problemas, pois, na realidade, não passam de meros exercícios. Esse mesmo autor alerta, ainda, que os professores não devem apresentar problemas muito difíceis para seus estudantes, uma vez que podem gerar a falta de interesse em resolvê-los.

\subsection{Resolução de problemas como metodologia de ensino}

De acordo com Schroeder e Lester (1989) e Onuchic e Allevato (2014) existem três concepções de resolução de problemas no ensino da Matemática: a primeira se refere a ensinar determinado conteúdo com o objetivo de empregá-lo na resolução de situaçõesproblema; a segunda é fazer uso de problemas como ponto de partida para a introdução de novos conceitos e a terceira perspectiva é o ensino mediante a resolução de problemas. É pertinente ressaltar que a experiência, aqui relatada, está inserida no terceiro contexto, no qual o emprego da metodologia de resolução de problemas visa o envolvimento dos estudantes no processo de aprendizagem da Matemática por meio do fazer Matemática (WALLE, 2009). Como aporte teórico para a aplicação dessa atividade, optou-se pelas técnicas propostas por George Polya, as quais são fundamentadas em princípios heurísticos que objetivam estabelecer métodos para a descoberta de soluções (MENEGUELLI et al., 2018).

George Polya foi o primeiro matemático a desenvolver uma heurística de resolução de problemas especificamente para a Matemática. Para Polya (1995), a condição essencial para que a resolução de problemas possa gerar efeitos positivos reside na escolha correta deles. Segundo o autor, "o aluno precisa compreender o problema, mas não só isso: deve também desejar resolvê-lo" (POLYA, 1995, p. 4). Na compreensão desse estudioso, a resolução de um problema deve compreender quatro fases, a saber: compreensão do problema, estabelecimento de um plano, execução do plano e retrospecto da resolução.

A primeira etapa consiste no entendimento do problema proposto, por meio da apropriação da situação e da leitura atenta do enunciado, de forma a identificar os dados e a incógnita. Echeverría e Pozo (1998) afirmam que não basta o entendimento da linguagem utilizada, mas, sobretudo perceber a profundidade e se colocar na busca de uma solução. Assim, é nesta etapa que o estudante toma conhecimento das orientações docentes frente ao problema apresentado.

A segunda fase se trata da criação de estratégias para resolver o problema. Para tanto, pode-se recorrer à busca de problemas semelhantes e às etapas que foram empregadas na resolução deles. De acordo com Polya (1995), tem-se definido um plano no momento em que se compreende o problema e é estabelecido um esboço de resolução, por meio da definição dos cálculos e/ou esquemas a serem aplicados.

$\mathrm{Na}$ execução do plano deve ser verificado cada passo, atendo-se para a relação existente entre os dados e os conceitos (AGUIAR; MACALÓS; LIMA, 2019). Vale ressaltar que não há uma linearidade a ser seguida e, consequentemente, ao executá-lo pode-se recair em 
novos problemas que necessitem da elaboração de novas estratégias (ECHEVERRÍA; POZO, 1998).

A última fase, caracterizada pelo retrospecto do processo, consiste em uma análise de todo o procedimento que envolveu a resolução do problema, levando os estudantes a explorarem e analisarem aquilo que foi construído. Além disso, verifica-se se há coerência entre o resultado encontrado de acordo com o problema proposto.

Ainda neste último passo, os discentes devem ser questionados se o problema poderia ser resolvido por outro caminho, sendo papel do professor propiciar tal reflexão (POLYA, 1995). Para os estudantes, esta etapa permite uma avaliação reflexiva da solução. Do ponto de vista didático, torna-se possível a reformulação de estratégias, aprimorando o desempenho heurístico dos discentes (ECHEVERRÍA; POZO, 1998).

Portanto, é relevante que o docente busque respeitar o ritmo de seus estudantes durante o todo o processo, além de utilizar exemplos e/ou contraexemplos, objetivando a análise de todo o procedimento resolutivo, não limitando seu envolvimento à correção da resposta final. Ressalta-se, ainda, a importância da participação efetiva dos discentes em todas as etapas da investigação.

\section{Procedimentos metodológicos}

Em consonância com a matriz curricular da escola e com a metodologia de resolução de problemas, estruturou-se uma proposta de aula sobre operações com frações. A ideia constituiu em criar uma atividade inovadora e desafiadora para os estudantes. Ressalta-se, aqui, que para uma atividade ser considerada inovadora, ela deve utilizar abordagens pedagógicas que ultrapassem as barreiras acadêmicas, para proporcionar aulas que não se baseiem, apenas, no modelo considerado tradicional de ensino (VALENTE, 2018). Nesta perspectiva, compreende-se que inovar uma proposta não implica em apresentar algo novo ou inédito, mas sim readequar, reestruturar e/ou aprimorar uma ideia já existente, mediante a criatividade que pode ser dedicada ao currículo, à avaliação ou à metodologia.

Assim, a prática descrita a seguir foi realizada no primeiro semestre do ano de 2020 com cinco turmas de 60 ano (11 a 12 anos), cada uma composta por 35 estudantes, em uma escola da rede privada da cidade de Porto Alegre - RS. Utilizou-se dois períodos de aula seguidos, com duração de cinquenta minutos cada um. Para a aplicação das atividades, feita por uma das autoras desta pesquisa, usou-se a ferramenta Google Meet, que se trata de um recurso gratuito para videochamadas online. Tal recurso já estava sendo utilizado para a realização das aulas na modalidade online, em função da pandemia da COVID-19. Cabe salientar que todos os discentes do grupo participante têm acesso à internet e utilizam smartphones, computadores ou tablets para o acesso às aulas na modalidade remota. Para tanto, no momento da atividade, solicitou-se que dispusessem dos seguintes materiais: caderno, lápis e borracha.

Vale destacar que esta proposta corresponde a uma adaptação de uma prática já realizada em anos anteriores, na modalidade de aulas presenciais. A caça ao tesouro, como era denominada, consistia em que os estudantes decifrassem enigmas para buscar novas pistas pela escola e encontrassem, ao final, um baú com moedas feitas de chocolate. Tal ideia, elaborada pelas autoras, foi reestruturada e adequada ao modelo online de educação.

O desenvolvimento desta aula se mostrou semelhante em todas as cinco turmas e, portanto, os resultados e as discussões serão descritos de maneira geral. Assim, apresentam- 
se, na sequência, as etapas da atividade, descritas em quatro momentos, construídos sob a perspectiva de Polya (1995).

\subsection{Iniciando a atividade}

Para iniciar a atividade, cada uma das turmas encontrou-se com a docente no horário habitual da aula de Matemática por meio do Google Meet. A proposta então foi descrita, explicando aos discentes que o objetivo da aula seria o de utilizar uma metodologia diferente para que fosse possível decifrar um enigma. Assim, como o tópico estudado no momento consistia nas operações com frações, estruturou-se um conjunto de atividades que, juntas, culminaram na resolução do enigma: a formação de uma frase secreta.

Na ferramenta Google Sala de Aula, destinada à publicação de tarefas e interação entre os usuários, já utilizada pela escola, disponibilizou-se uma pasta para cada estudante com todos os seis desafios necessários para a realização da atividade e a Figura 1 exemplifica como os discentes a visualizavam em seus dispositivos.

Figura 1: Captura de tela dos arquivos disponibilizados aos estudantes

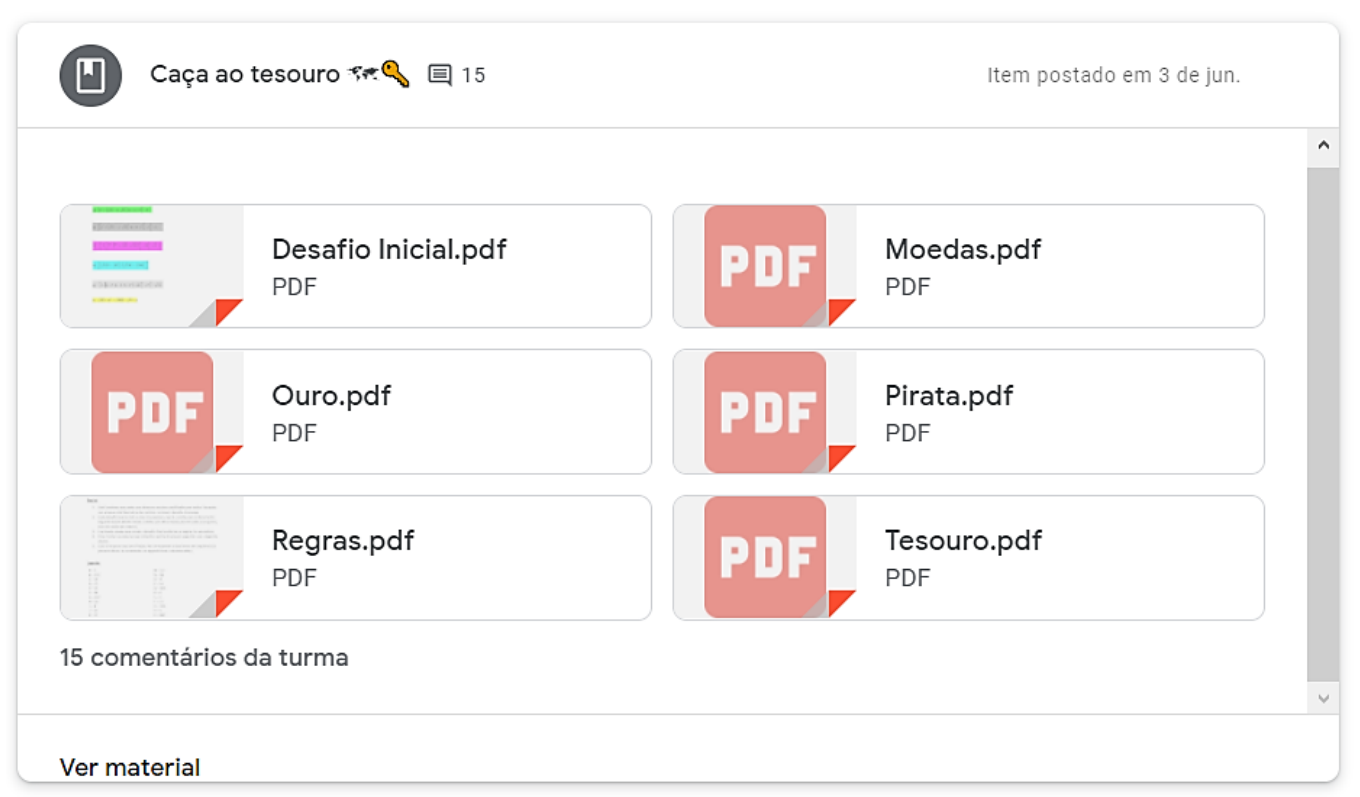

Fonte: a pesquisa.

Cabe salientar que, para o início da atividade, orientou-se que o arquivo "Regras" fosse aberto para que todos pudessem compreender as normas e etapas desta aula. Tais regras estão apresentadas na Figura 2. 
Figura 2: Regras da atividade

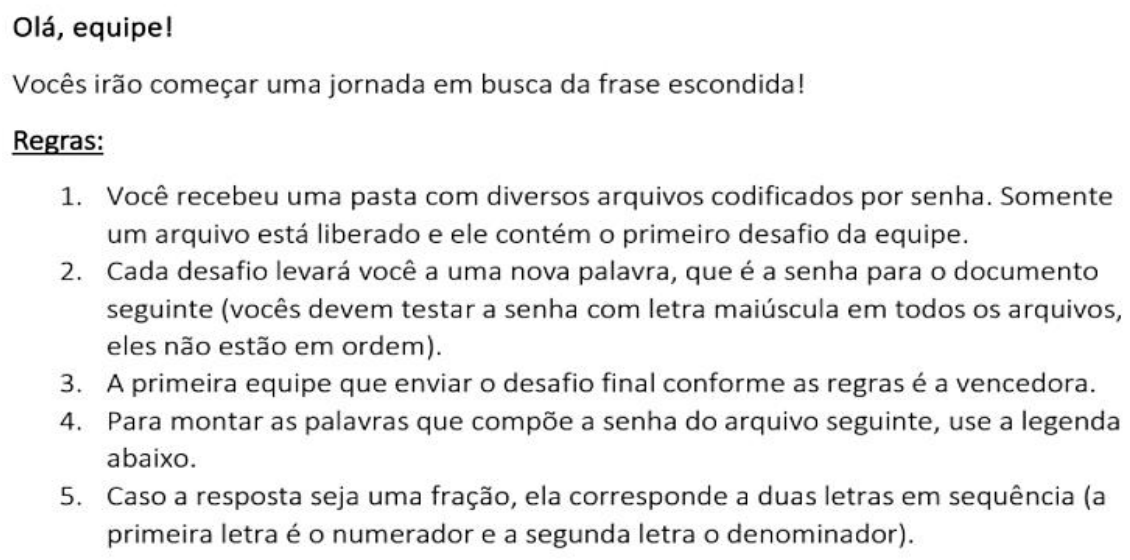

Legenda:

$\begin{array}{ll}\text { A }-5 & \mathrm{~N}-16 \\ \mathrm{~B}-4 & \mathrm{O}-89 \\ \mathrm{C}-18 & \mathrm{P}-7 \\ \mathrm{D}-25 & \mathrm{Q}-11 \\ \mathrm{E}-3 & \mathrm{R}-13 \\ \mathrm{~F}-12 & \mathrm{~S}-8 \\ \mathrm{G}-36 & \mathrm{~T}-301 \\ \mathrm{H}-9 & \mathrm{U}-21 \\ \mathrm{I}-19 & \mathrm{~V}-23 \\ \mathrm{~J}-10 & \mathrm{X}-24 \\ \mathrm{~K}-27 & \mathrm{Y}-31 \\ \mathrm{~L}-19 & \mathrm{Z}-98 \\ \mathrm{M}-1 & \end{array}$

Fonte: elaborado pelas autoras.

Após a leitura das regras, devia-se abrir o arquivo "Desafio inicial" que continha o primeiro conjunto de tarefas matemáticas a serem resolvidas. É pertinente ressaltar que para cada resposta numérica havia uma letra correspondente. Assim, ao final de cada um dos desafios, uma palavra seria formada e essa seria a senha para abrir um novo arquivo com o próximo desafio. Acentua-se que os arquivos restantes ("Ouro", "Moedas", "Pirata e "Tesouro" - ver Figura 1), cujos títulos fazem alusão ao caça ao tesouro das aulas presenciais, só abriam com senha e não se divulgou aos estudantes a ordem correta de abertura dos arquivos. Assim, ao descobrirem uma palavra, os discentes deveriam testá-la como senha em todos os outros arquivos restantes para verificar qual deles abriria.

O último desafio, apresentado na Figura 3, consistiu na organização de todas as palavras descobertas - que foram utilizadas como senhas para abertura dos arquivos - na seguinte frase: NÓS DECIFRAMOS ESTE ENIGMA. Os estudantes que finalizassem primeiro e, portanto, descobrissem a frase escondida, deveriam gravar um vídeo dizendo a frase em voz alta, e enviar para um endereço de e-mail previamente informado. Assim, quem enviasse o email mais rapidamente, seria considerado o vencedor daquela turma. 
Figura 3: O último desafio

Parabéns, equipe!

Vocês chegaram ao último desafio.

Ele é super simples: basta vocês organizarem as palavras encontradas nos desafios anteriores e formarem a frase escondida.

Depois que vocês descobrirem a frase, gravem um vídeo da reunião do Google Meet em que todos apareçam falando a frase bem alto e enviem para o e-mail informado.

Fonte: elaborado pelas autoras.

É importante ressaltar aqui que, além das tarefas matemáticas já desenvolvidas pelos estudantes nos desafios anteriores, há outros desafios tecnológicos envolvidos: a gravação de um vídeo, em que todos os integrantes apareçam, apesar de não estarem no mesmo local fisicamente e o envio de um e-mail com um anexo em formato de vídeo. Salienta-se que, embora os discentes desta faixa etária sejam considerados nativos digitais (PRENSKY, 2001), percebeu-se que não consideraram trivial gravar o vídeo, tampouco enviá-lo à docente.

\subsection{Definindo estratégias em grupos}

Para que a atividade fosse realizada, dividiu-se cada uma das turmas em cinco grupos de sete integrantes cada, criando-se uma sala do Google Meet para que cada grupo pudesse se reunir e discutir sobre as melhores estratégias para atingir o objetivo. Destaca-se que esta divisão foi feita pela docente, de acordo com a afinidade demonstrada entre os estudantes ao longo do ano letivo.

Enfatiza-se que, durante todo o desenvolvimento da atividade, a professora ficou alternando entre as distintas salas do Meet com a finalidade de auxiliar os grupos em suas dúvidas, além de observar suas estratégias adotadas na resolução do enigma. Sobre isso, destaca-se a satisfação geral de todas as turmas em relação ao trabalho em grupo, uma vez que muitos relataram sentir falta de realizar atividades em equipe durante este período de aulas remotas.

Assim, os integrantes das equipes discutiram, nos primeiros minutos da atividade, quais seriam suas estratégias para alcançar o objetivo principal: descobrir a frase secreta e finalizar a atividade antes dos outros grupos. Destaca-se, aqui, o fato de que o tempo para a execução das tarefas era uma variável primordial e, portanto, os estudantes se organizaram levando isso em conta, tentando otimizar as resoluções da melhor forma possível.

Ao se depararem com o desafio inicial, as equipes criaram diferentes estratégias para sua resolução. Verificou-se que a maioria dos grupos definiu que cada integrante resolveria um item das tarefas propostas e, ao final, compartilharia sua solução com os demais integrantes pelo Google Meet. Em alguns grupos, determinou-se que mais de um estudante ficaria responsável pelo mesmo item, a fim de determinar uma checagem dupla da resposta, no intuito de evitarem atrasos na resolução do desafio principal. 


\title{
3.3 Executando o plano
}

No momento de colocarem em prática seus conhecimentos matemáticos para solucionarem as atividades propostas, as equipes acordaram diferentes formas da leitura dos problemas. Alguns grupos escolheram utilizar o recurso do compartilhamento de telas para que todos pudessem visualizar o mesmo arquivo ao mesmo tempo, enquanto outros escolheram realizar a leitura das tarefas de forma individual para, depois, concluírem o trabalho coletivamente. Para tanto, solicitou-se que a resolução das atividades fosse feita no caderno de matemática, que poderia ser consultado, bem como o livro de matemática adotado pela escola. A Figura 4 exemplifica alguns dos problemas propostos aos estudantes, cuja palavra formada ao final é ENIGMA.

Figura 4: Exemplos dos problemas propostos

\begin{abstract}
Júlia acertou $\frac{5}{8}$ da prova de matemática, deixou $\frac{3}{16}$ em branco e errou o restante das questões. Determine a fração que representa as questões que Júlia respondeu de maneira incorreta.
\end{abstract}

Rodrigo recebe, por mês, $\mathrm{R} \$ 1.656,00$ como remuneração por seu trabalho. Desse valor, $\frac{1}{4}$ é utilizado para o pagamento de seu aluguel, $\frac{3}{8}$ são gastos em sua alimentação, $\frac{2}{9}$ nas contas de luz, água e gás e o restante é gasto com lazer. Qual fração de seu salário Rodrigo gasta com lazer e alimentação?

Olívio é um plantador de soja. No mês passado, com o tempo a seu favor, ele conseguiu colher $\frac{3}{10}$ de tonelada de soja. Assim, ele formou um estoque de tonelada de $\frac{1}{2}$ soja. Que fração de tonelada de soja Olívio tinha como estoque, antes da colheita do mês passado?

SENHA DO PRÓXIMO ARQUIVO:

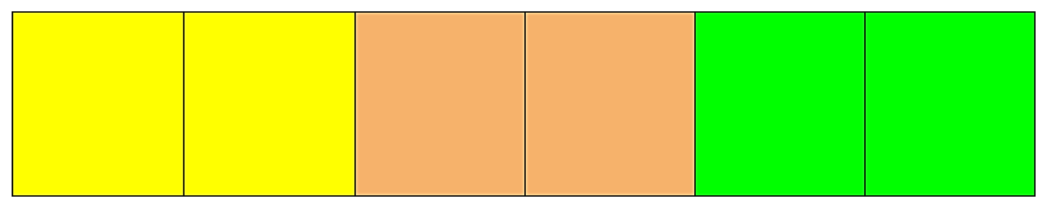

Fonte: elaborado pelas autoras.

Finalizados todos os itens propostos de cada um dos desafios, os estudantes retornaram ao arquivo "Regras" para fazerem a associação de suas respostas com as letras correspondentes, a fim de encontrarem a palavra que determinaria a senha do próximo arquivo.

Sobre isso, salienta-se a forma na qual o desafio foi criado, uma vez que possibilitou um rápido feedback aos estudantes. Ao se depararem com letras que não formavam uma palavra conhecida ou com números que não estavam presentes na legenda de letras, ficou claro que o resultado não estava correto e, assim, pôde-se repensar sobre a estratégia de 
resolução antes mesmo da finalização de toda a atividade. Portanto, esta etapa da execução do plano demandou uma reflexão, caracterizada pela revisão das ações e esses questionamentos à estratégia inicial ocorreram de forma quase que síncrona à execução das estratégias de resolução e determinação dos resultados.

Evidencia-se que todos os arquivos consistiram em uma lógica semelhante de resolução: solucionar as tarefas matemáticas, relacionar com as letras da legenda, determinar a senha do próximo arquivo e descobrir qual seria esse arquivo.

\subsection{Refletindo sobre a atividade}

No quarto e último momento da aula, fez-se um encerramento da atividade com toda a turma. Para tanto, solicitou-se que todos os estudantes retornassem à sala inicial do Google Meet para que os resultados fossem apurados e divulgados com todos os integrantes da turma ao mesmo tempo.

É pertinente ressaltar que, enquanto a docente transitava entre os diferentes grupos, os e-mails com os vídeos do último desafio eram recebidos por ela. Assim, após a conferência da frase, determinou-se o ranking dos primeiros três grupos a enviarem o vídeo do desafio final, com o enigma decifrado. O critério utilizado para tal classificação, além da determinação da frase correta, consistiu na hora do recebimento do referido e-mail. Em algumas turmas, a diferença foi de apenas um minuto entre o primeiro e o segundo grupos colocados, acirrando ainda mais o clima de expectativa entre os participantes.

Antes da divulgação do resultado, os discentes foram questionados sobre suas estratégias e convidados a compartilharem com o restante da turma as combinações feitas em suas equipes. Observou-se que este momento de análise se mostrou relevante, dado que os estudantes escutaram de forma atenta às distintas estratégias e aos diferentes métodos e planos adotados por outros grupos.

\section{Comentários da aplicação da atividade}

Diante da aplicação desta atividade, considera-se oportuno discutir alguns aspectos, de acordo com as etapas da aula em questão. O primeiro deles diz respeito à necessidade da adaptação de propostas que, originalmente, eram aplicadas na modalidade presencial. 0 cenário pandêmico da COVID-19 tem propiciado um repensar por parte docente acerca das práticas adotadas em sala de aula, que tiveram de ser adaptadas a uma nova realidade. Sobre isso, Cani et al. (2020, p. 30) levantam a seguinte reflexão: "Estamos, desse modo, envolvidos em novos letramentos, novas práticas, novos meios de construir conhecimento e de estabelecer comunicação e, por que não, de fazer acontecer a educação".

Neste contexto, Pontes (2019) se questiona se os educadores estão capacitados para atuarem nesta cultura digital a qual estamos inseridos, sobretudo as nossas crianças, que já nasceram nesta realidade. Segundo o autor, é primordial que os docentes sejam competentes para estabelecer uma proximidade com seus discentes para que se consiga, assim, uma relação prazerosa com eles (PONTES, 2019).

A respeito da cultura digital, Valente (2018) sugere algumas inovações no ensino e na aprendizagem mediadas pelas tecnologias digitais, enfatizando metodologias ativas. Assim, frente à situação enfrentada, em vez de suspender esta prática, buscou-se estudar a melhor maneira de ajustá-la ao ensino online, dado que os estudantes sempre demonstraram muito engajamento e entusiasmo quando realizada presencialmente. Cabe salientar que nesta 
aplicação remota as opiniões continuaram na mesma linha, dado que, quando questionados ao final da aula, praticamente todos os estudantes afirmaram ter gostado muito da proposta. A Figura 5 apresenta dois exemplos desses comentários.

Figura 5: Comentários dos estudantes sobre a prática "Decifrando o enigma"

Eu gostei porque achei diferente e interessante usar aqueles códigos para abrir mais desafios, além de uma competitividade divertida.

EU AMEIIII, foi uma atividade descontraída, e que ao mesmo tempo aprendemos bastante!

Fonte: a pesquisa.

Considera-se que o principal motivo do significativo envolvimento e comprometimento dos discentes com esta atividade está relacionado ao desafio, em virtude de terem sido instigados a resolverem um problema. Para Polya (1995), resolver um problema é encontrar um caminho, ainda não conhecido, que supere obstáculos para que se consiga alcançar o objetivo final. E, neste caso, pode-se afirmar que foi exatamente isso que os estudantes vivenciaram.

De acordo com Pontes (2019), é relevante que o ensino da Matemática se preocupe em propiciar condições às quais o discente possa desenvolver a autonomia para relacionar situações da sala de aula com problemas reais do cotidiano. Nesse sentido, Onuchic e Allevato (2011) enfatizam que a resolução de problemas pode auxiliar o professor no sentido de proporcionar aos estudantes o protagonismo, concedendo mais responsabilidades por suas aprendizagens. Assim, é imprescindível que o discente compreenda e assuma seu papel responsável destes cenários.

Outro aspecto a ser destacado diz respeito à possibilidade de se definir estratégias a partir do trabalho em grupo, na modalidade online de aulas. Conquanto não seja uma tarefa simples, é fundamental que o docente busque por metodologias que priorizem a interação, o diálogo e a organização do estudo em equipes. Nesse contexto, a resolução de problemas "pressupõe aulas de Matemática com professores e alunos envolvidos em comunidades de aprendizagem, desempenhando diferentes papéis e responsabilidades, visando a promover uma aprendizagem mais significativa" (MORAIS; ONUCHIC, 2014, p.17).

Conforme já mencionado, cada grupo estabeleceu um plano de trabalho para que conseguisse atingir o objetivo final. Nesse tipo de prática, "o método permite uma elasticidade e variação, admite abordagens diversas" (POLYA, 1995, p. 14) e, portanto, é válido ressaltar as distintas táticas adotadas pelas equipes, que se organizaram da maneira que julgaram mais adequada.

Muitas das respostas dos estudantes sobre se haviam gostado de descobrir o enigma enfatizaram o trabalho em grupo, como pode ser visto na Figura 6, a partir do comentário de três discentes. Destaca-se que foi um item muito ressaltado pelas turmas como algo positivo sendo, inclusive, solicitado para atividades posteriores. 
Figura 6: Opinião dos estudantes sobre o trabalho em equipes

Eu gostei porque foi diferente foi feita em grupo mesmo com o distanciamento

Gostei bastante, porque foi muito divertido trabalhar em grupos para achar o resultado.

Sim, porque eu revisei os conteúdos vistos em aula e ao mesmo tempo eu me diverti com meus amigos.

Fonte: a pesquisa.

O próximo elemento a ser discutido está na execução do plano por parte dos estudantes. Definidas as estratégias e a organização de trabalho de cada grupo, as equipes partiram para o momento mais prático, que exigiu conhecimentos matemáticos para que conseguissem solucionar as tarefas propostas. De acordo com Pontes (2019, p. 5), "a execução do plano só será eficaz se todo o planejamento desde a sua compreensão até as estratégias a seguir forem realizadas plenamente". Assim, segundo Onuchic e Allevato (2011), esta etapa possibilita o desenvolvimento de habilidades matemáticas, promovendo o entendimento de conceitos e de conteúdos.

Salienta-se que, não somente nesta fase, mas em todos os outros momentos da resolução de problemas, a relevância da intervenção docente mediante questionamentos, a fim de que os estudantes avancem no trabalho, e suscitando o gosto pela atividade, despertando a curiosidade por parte dos discentes. A respeito disso, Echeverría e Pozo (1998) comentam que, para Polya, os discentes devem ser questionados sobre os dados disponíveis nos problemas, a incógnita a ser descoberta, a existência de outros problemas semelhantes ao proposto que, de alguma forma, possam contribuir no entendimento.

Neste cenário, ficou claro que, de fato, o que pode ser entendido como problema para um estudante, para outro pode ser um mero exercício, conforme já discutido anteriormente. Por meio de alguns comentários dos discentes, identificou-se que, para determinados estudantes, as atividades propostas pareceram complexas, conforme ilustrado na Figura 7.

Figura 7: Você gostou da atividade?

sim gostei mas só da frase dos cálculos não

achei legal mas muito demorado e puxado

Fonte: a pesquisa. 
A respeito da reflexão estabelecida ao final do encontro, novamente com todos os estudantes de cada uma das turmas, foi possível retomar o objetivo da aula a partir da análise dos procedimentos que envolveu a resolução do problema. De acordo com Polya (1995), esta etapa é relevante para os estudantes, pois "se fizerem um retrospecto da resolução completa, reconsiderando e reexaminando o resultado final e o caminho que levou até este, eles poderão consolidar o seu conhecimento e aperfeiçoar a sua capacidade de resolver problemas" (POLYA, 1995, p. 10).

Neste momento foi possível compartilhar com toda a turma as distintas organizações adotadas pelos grupos. Sobre isso, observou-se que o trabalho em equipes foi positivo, pois como discentes de mesma idade utilizam linguagens semelhantes, a comunicação e os auxílios que ocorreram dentro de cada equipe foram muito positivos. Vale destacar que, alguns discentes relataram que determinados resultados não pareciam estar de acordo com as letras encontradas na legenda, mas, mesmo assim, conseguiram inferir a possível palavra como senha para abrir o próximo arquivo. Sobre isso, enfatiza-se que, embora o esperado fosse que todos os cálculos fossem realizados e de maneira correta, considera-se a solução relatada como uma estratégia válida para que o objetivo de decifrar o enigma fosse atingido.

Por fim, cabe colocar, ainda, algumas das vantagens e limitações encontradas com a aplicação desta atividade. A respeito da aplicação desta prática na modalidade online, salienta-se que o uso das senhas pode ser considerado como um ganho em virtude de não ser possível de ser feito, da mesma forma, nas aulas presenciais. Sobre isso, ressalta-se o rápido feedback proporcionado pela tecnologia na verificação da palavra como correta ou incorreta.

Desta maneira, considera-se que o uso de recursos digitais deve estar relacionado a aulas que busquem por inovações e não somente réplicas de práticas já conhecidas e aplicadas sem a utilização destas ferramentas. A respeito disso, Valente (2018) afirma que para que haja mudança de paradigma em relação a práxis educativa, é necessária uma transformação no modo como os conteúdos são desenvolvidos, de forma a contemplar as vivências cotidianas dos estudantes que são mediadas pelas TDIC.

Em contrapartida, nesta aula, assim como em outros encontros na modalidade online, houve estudantes com problemas no acesso à internet que, em alguns momentos estiveram com o sinal da conexão instável e, portanto, a participação na atividade ficou um pouco prejudicada, além das imagens e/ou o áudio que acabaram por travar de vez em quando.

\section{Considerações finais}

Este artigo teve por objetivo apresentar o relato de uma experiência realizada com cinco turmas de 60 ano denominada "Decifrando o enigma" que, sob a perspectiva da resolução de problemas proposta por George Polya, trabalhou com as quatro operações com frações mediante uma prática de aula remota. Na atividade, realizada em grupos, os estudantes deveriam encontrar palavras - a partir de uma legenda numérica - que, ao serem colocadas juntas, formavam uma frase secreta.

Para tanto, tal atividade contou com a aplicação das quatro fases definidas por Polya (1995) para resolver um problema: a compreensão do problema, a construção de um plano de ação, a execução do plano e o retrospecto. Na tarefa proposta, pode-se observar essas quatro fases de forma evidente, uma vez que toda sua dinâmica foi baseada na resolução de um problema: decifrar o enigma. Considera-se que o uso da tecnologia contribuiu para que as fases da execução e retrospecto acontecessem quase que simultaneamente, devido ao rápido feedback da dinâmica utilizada. 
Diante da circunstância da pandemia da COVID-19, tornou-se necessário replanejar e readequar práticas pedagógicas para a modalidade de aulas remotas que, usualmente, eram feitas presencialmente. Sobre isso, Cani et al. (2020) afirmam que, de fato, as TDIC passaram a fazer parte do cotidiano escolar neste momento singular. Desta forma, cabe ao docente sair de sua zona de conforto, mostrando-se aberto a testar novos modelos, buscando por inovação em suas aulas.

A atividade aqui descrita não exigiu conhecimentos avançados sobre recursos digitais, apenas uma reestruturação do que já era feito presencialmente. O Google Meet e o Google Sala de Aula já estavam sendo usados na escola, sendo necessário, somente a criação de senhas para os arquivos.

É válido destacar, ainda, que o método de trabalho adotado nesta aula foi amplamente elogiado pelas turmas, que solicitaram que este tipo de prática se repetisse com mais frequência. A maioria dos estudantes afirmou que esta atividade os auxiliou a exercitar o conteúdo de uma maneira divertida, feita conjuntamente com seus amigos.

Por meio da resolução de problemas a criança atiça sua curiosidade e desenvolve a arte de criar e ampliar seu meio de convívio (PONTES, 2019, p. 3). Neste cenário, evidencia-se que esta metodologia foi utilizada em uma aula de que visou o trabalho das operações com frações. No entanto, ela poderia ter sido aplicada a outros tópicos da matriz curricular. Esperase que este relato desperte a motivação para novas práticas na Educação Básica e que as propostas aqui descritas sirvam de inspiração para outras aplicações com professores de distintas áreas do conhecimento.

\section{Referências}

AGUIAR, Rogério de; MACALÓS, Larissa Vieira; LIMA Jeferson Moizés. A Técnica De Polya: Uma Atividade Contextualizada Sobre Função Exponencial Envolvendo O Uso De Contraceptivos.

Revemat: Revista Eletrônica de Educação Matemática, v. 14, ed. 1, p. 1-18, 2019.

BRASIL. Ministério da Educação. Secretaria de Educação Fundamental. Parâmetros Curriculares Nacionais (1 e $\mathbf{2}^{\circ}$ ciclo): Matemática. MEC/SEF. Brasília, 1998.

BRASIL. Ministério da Educação. Secretaria de Educação Fundamental. Base Nacional Comum Curricular: A área de Matemática. Brasília, 2018.

CANI, Josiane Brunetti; SANDRINI, Elizabete Gerlânia Caron; SOARES, Gilvan Mateus; SCALZER, Kamila. Educação e COVID-19: a arte de reinventar a escola mediando a aprendizagem “prioritariamente" pelas TDIC. Revista Ifes Ciência, [s. I.], v. 6, ed. 1, p. 13-29, 2020.

ECHEVERRÍA, María del Puy Pérez. A solução de problemas em Matemática. In: POZO, Juan Ignacio (Org.). A Solução de Problemas. Porto Alegre: ARTMED, p. 43-63, 1998.

ECHEVERRÍA, María del Puy Pérez; POZO, Juan Ignacio. Aprender a resolver problemas e resolver problemas para aprender. In: POZO, J. I. (Org.). A Solução de Problemas. Porto Alegre: ARTMED, p. 13-41, 1998.

MAIA, Érika Janine; PROENÇA, Marcelo Carlos de. A resolução de problemas no ensino da geometria: dificuldades e limites de graduandos de um curso de pedagogia. Revemat: Revista Eletrônica de Educação Matemática, v. 11, n. 2, p. 402-417, 2016.

MENEGHELLI, Juliana; CARDOZO, Dione; POSSAMAI, Janaína Poffo; SILVA, Viviane Clotilde da. Metodologia de resolução de problemas: concepções e estratégias de ensino. RBECT: Revista Brasileira de Ensino de Ciência e Tecnologia, Ponta Grossa, v. 11, ed. 3, p. 211-231, set./dez. 2018. 
MORAIS, Rosilda dos Santos; ONUCHIC, Lourdes de La Rosa. Uma abordagem histórica da resolução de problemas. In: ONUCHIC, Lourdes de La Rosa et al. Resolução de problemas: teoria e prática. Jundiaí: Paco Editorial, 2014, p.13-28.

ONUCHIC, Lourdes de La Rosa; ALLEVATO, Norma Suely Gomes. Pesquisa em Resolução de Problemas: caminhos, avanços e novas perspectivas. BOLEMA: Boletim de Educação Matemática, Rio Claro, v. 25, ed. 41, p. 73-98, dez 2011.

ONUCHIC, Lourdes de La Rosa; ALLEVATO, Norma Suely Gomes. Ensino-Aprendizagem-Avaliação de Matemática: por que através da resolução de problemas? In: ONUCHIC, Lourdes de La Rosa et al. Resolução de problemas: teoria e prática. Jundiaí: Paco Editorial, 2014, p. 29-44.

POLYA, George. A arte de resolver problemas: um novo aspecto do método matemático. Rio de Janeiro: Interciência, 1995.

PONTES, Edel Alexandre Silva. Método de Polya para resolução de problemas matemáticos: uma proposta metodológica para o ensino e aprendizagem de matemática na educação básica. HOLOS, v. 3, p. 1-9, dez. 2019.

PRENSKY, Marc. Nativos Digitais, Imigrantes Digitais. On the Horizon. MCB University Press, v. 9, n. 5, 2001.

SCHROEDER, Thomas. L.; JR. LESTER, Frank. K. Developing Understanding in Mathematics via Problem Solving. In: New Directions for Elementary School Mathematics. cap. 3, p. 31-40, 1989.

VALENTE, José Armando. Inovação nos processos de ensino e de aprendizagem: o papel das tecnologias digitais. In: VALENTE, José Armando et al. Tecnologia e educação: passado, presente e o que está por vir. Campinas: NIED/UNICAMP, 2018. cap. 1, p. 17-41.

VIANNA, Carlos Roberto. Resolução de Problemas. In: TEMAS em Educação I. Curitiba: Futuro Congressos e Eventos, 2002, p. 401-410.

WALLE, John A. Van del. Ensinando pela resolução de problemas. In: WALLE, J A. V. Matemática no ensino fundamental: formação de professores e aplicação em sala de aula. Porto Alegre: Artmed, 2009, p. 57-81. 